\title{
MIMR ISSUES AND CHALLENGES OF PUBLIC HEALTH ACCESSIBILITY AMONG URBAN POOR PEOPLE: A CASE STUDY OF MALAYSIA, IRAN AND INDIA
}

\author{
Tumin Makmor ${ }^{1 *}$, Sohrabi Maryam ${ }^{1}$, Osman Ahmad Farid ${ }^{2}$ \\ ${ }^{1}$ Department of Administrative Studies \& Politics, Faculty of Economics and \\ Administration Building, University of Malaya, Malaysia \\ ${ }^{2}$ Centre for Poverty and Development studies, Faculty of Economics and \\ Administration, University of Malaya, Malaysia \\ *Corresponding Author’s Email: makmor@um.edu.my
}

\begin{abstract}
Public health care clinics accessibility is known as an important issue for urban poverty level residences who have lower financial resources and facilities. The objectives of this study is overviewing and explaining the issues and challenges of public health accessibility among urban poor in three Asian countries i.e. Malaysia, Iran and India. This study used the method of literature review from online sources include: government documents, articles and publications related to poverty and health care access. All the papers were filtered for the different variables based on the model presented by the Institute of Medicine. Access concern exists in all three countries, only types and sources of the barriers are varying. Differences influence public expectations and opinion of policy makers. In general some Malaysian and Iranian do not have enough access to public health care providers in spite of a good coverage of healthcare services through public clinics in Malaysia and an acceptable coverage through health posts and health centers in Iran. India still faces so many structural, financial and personal barriers to deliver health care services through public urban health posts and urban family welfares.
\end{abstract}

Keywords: Healthcare, Public Clinics, Barriers, Asia, Poverty

\section{INTRODUCTION}

To maintain population health, primary care is the most important issue which is inexpensive and easy to deliver in a shorter waiting time than inpatient and specialty care -(Guagliardo, 2004, WHO, 2008). Even though Asia is the most dynamic and fastest growing region in the world, most of the Asian governments' budget on public health is not enough and often not focused on those who need it more. For many people in this region, health expenses are the major cause of poverty (Asian Development Bank, 2014).

Even with unbelievable improvements in health since 1950 , there are still a number of challenges, which should be solved easily (Shah, 2014). One longstanding and polarized debate in global health concerns is the appropriate role and balance of the public and private sector in providing health care services to populations in low and middle income countries (Berendes et al., 2011). Since Public Sector delivers services at a very low cost and perhaps it is "fair" in the sense that no one is excluded from getting care on the basis of ability to pay. On the other hand, the perception that private care has better quality, or the greater convenience of private care lead a large number of people to pay for services that they could otherwise get for free or at a highly subsidized rate (Shepard et al., 2002). Interestingly, Basu et al. (2012) proved that usually private sector is not more efficient, accountable, or medically effective than the public sector, anyway, the public sector appears frequently to lack timeliness and hospitality towards patients (Heller, 1982). People in poor countries tend to have less access to health services than those in the better-off countries, and within countries, the poor have less access to health services (Peters et al., 2008) and receive lower quality and quantity of care (Arcury et $a l ., 2005)$.

Around $60 \%$ of world's population lives in Asia. $54 \%$ of Asia region is urban, so, majority of the world's population live in urban areas (Sclar et al., 2005) and more than a third of the world's poor live in India (Butsch et al., 2012). Nowadays, urban health has become a highly diverse research topic (Butsch et al., 2012), and public health care clinics' accessibility is known as an important issue for urban poverty level residences who have lower financial resources and facilities. Since urban poor have more health problems due to different life style, their accessibility to health 
care services can affect their quality of life. Delivery of health service to patients will be limited by barriers in the difference of health outcomes for those who involve less or more barriers (Shook, 2005). Urban health is very important because the annual urban growth rate is $3.2 \%$ which is much higher than rural area. By the year 2030 , the number of residence in urban area will reach to 1.4 billion (Laquian, 2004). Statistics for the three targeted countries show that $1.7 \%$ of the total population in Malaysia, $18.7 \%$ of Iranian and $21.95 \%$ of Indian in India are living in poverty (World Bank, 2013).

This study aims to overview and explain the state, issues and challenges of public health accessibility among urban poor in Malaysia, Iran and India. According to the health indicators in these three countries, immunization coverage in Malaysia (97\%) and Iran (98\%) are reasonably high compared to India $(72 \%)$, similarly life expectancy at birth in India (66 years) is lower than Malaysia (75 years) and Iran (74 years), yet, death rate in all these three countries are the same (5 per 1000 people). On the other hand, infant mortality rate (per 1000 live birth) in Malaysia is 6, in Iran 21, and in India 200. The extent of change and improvement in these three countries' healthcare system over the past decades are remarkable in spite of passing financial crisis, revolution and independency experience.

Public health care system in Malaysia: Ministry of Health centrally administer public sector health services through its district, state and central offices. This ministry regulates and plans pharmaceutical industry and most public sector health services but so far exert little regulatory power over the private sector (WHO, 2012). The number of public primary care facilities which is currently 1025 centers and over 2000 small community clinics, and dental clinics were expanded steadily in earlier decades, particularly to reach people in under-served rural areas. Mainly primary health care services deliver through public clinics across the country (WHO, 2012). According to the World Bank, health expenditure; total (percent of GDP) in Malaysia was last measured at 3.9 in 2013. Health expenditure; public (percent of total health expenditure) in Malaysia was last measured at 55.0 in 2013.
Public health care system in Iran: The Ministry of Health and Medical Education is in charge for regulating both the public and private sector to deliver healthcare services (Alavian, 2007). Within the last six years Iran has endeavoured to implement an urban family physician program to remedy some of the problems, as well as improving the low socioeconomic groups' access to health care which covers more than 30 million individuals (Rashidian, 2014). Over the last two decades, public sector become the main provider of primary health care services across the country (Mehrdad, 2009). Over 2300 Urban Health Centres (UHCs), each with at least three general physicians and 15 health workers, cover a population of approximately 15,000 people -(Asadi-Lari et al., 2004). According to the World Bank, health expenditure; total (percent of GDP) in Iran was last measured at 6.7 in 2013. Health expenditure; public (percent of total health expenditure) in Iran was last measured at 40.4 in 2013.

Public health care system in India: health care system in India looks like a model to deliver a universal health services in a large and poor country. Its extensive three-tire design ensures that all households in both urban and rural are close to a free government health services. In India each state has its own health care delivery system in both private and public sector. While each state is responsible for the functioning of their respective health care system, federal government has certain responsibilities such as: providing funding to implement national programs, coordinating and evaluating the work of various provincial health authorities, assisting, guiding, planning and policy making (Peter Wennerholm, 2013). A total of 1083 urban family welfare centers and 871 health posts are functioning as the main public sector sources of primary health care services for urban poor and urban slum dwellers. All of the hospitals also provide primary health care services, even those which providing secondary or tertiary care. On average, an urban health post covers 62603 urban poor whereas the average for an urban family welfare center is 48557 (MOHFW, 2003, Chander Shekhar, 2005). According to the World Bank, health expenditure; total (percent of GDP) in India was last measured at 4.0 in 2013. Health expenditure; public (percent of total health expenditure) in India was last measured at 31.1 in 2013. 


\section{RESEARCH METHODOLOGY}

Research question: research question of the literature was' what is known about the issues and challenges of public health accessibility among urban poor in Malaysia, Iran and India?'

Search strategy: The method that has been used is literature review was reviewing data and information from the World Bank Group data and latest governments' reports and documents form these three countries including Health Facts, Year Books, and Bulletins, as well as articles from databases of WHO, Science Direct, Pub Med, Medline, and Web of Knowledge, limited to articles published between 1982 and 2014. The database were searched using keywords such as; "health care access", " public clinic utilization", "health issues and challenges among poor", "Primary health care", and "barriers to access health care services".

Selection: The articles selected trough titles, keywords and abstracts.

Data Extraction: Available articles and reports have been reviewed and selected from different databases searches. The studies are not sufficiently comparable due to heterogeneity of the included studies. All the papers were filtered for the different variables based on the model presented by Institute of Medicine.

Theoretical framework: We used Institute of Medicine's Model of access to personal healthcare services (1993) to help arrange the potential barriers. In the IOM model access barriers are divided into three categories: personal, structural and financial. The subject is heading to three main groups which are "Structural Barriers", "Financial Barriers" and "Personal Barriers".

\section{RESULTS}

A Total of 45 articles and 14 reports out of 87 articles and 17 reports were found relevant to healthcare access barriers, issues and challenges.

Structural barriers: A well-organized distribution of resources between different levels of services and different geographical regions is critical to ensure the physical availability of a proper level of sufficient resource of health services (Balarajan et al., 2011, Banerjee et al., 2008). Individuals' distance to primary health care provider has direct effect on the childhood mortality which is well documented (Deogaonkar,
2004), especially for women, overcoming this through better transportation, roads, communication network or outreach is important '(Balarajan et al., 2011, Griffiths and Stephenson, 2001). Generally, 73-92\% of Indian urban people has less than $5 \mathrm{~km}$ distance to a public health services provider(Murray Aitken, 2013). Due to availability of transportation, urban areas have fewer challenges compare to rural areas in India, therefore, distance is not considered as an access barrier in urban areas (Aitken, 2013) but for Malaysia and Iran, transportation is considered a barrier to access health care services (Ghafari, 2014, HaghparastBidgoli et al., 2010).

According to the institute of medicine, access is not only seeking a doctor, but it is also referring to the ability of providing the medicine which can affect the outcome. For instance, in Malaysia, despite good coverage of the services provided by public healthcare sector, only $25 \%$ of generic medicines are available in public sectors(Babar et al., 2007).

In spite of lower cost of treatment in public sectors (2-9 times more affordable), even poor people prefer to use private healthcare facilities due to lack of human resources, facilities, adequate necessary medicines, poor physical environments, limited opening availability (Balarajan et al., 2011, Aitken, Chang \& Udeshi, 2013). In India, most of the studies reported absences of doctors, nurses, diagnosis facilities, low quality of the services (Balarajan et al., 2011, Deogaonkar, 2004) and long waiting time are the reasons for patients to not use public health care services or delay it. Around $75 \%$ of visits in urban areas were to private clinics and hospitals and the remaining $25 \%$ were evenly divided between hospitals and primary health centers (Das and Hammer, 2007).

A research in Malaysia shows that time constraint, long waiting time, negative attitude of healthcare provider and long distance are the most important barriers for youth to not use healthcare services (Ghafari et al, 2014, Heller, 1982). Based on studies in Iran, high work load, too much patients, and responsibility for too many tasks force the service provider to spend less time for each patient, which lead to lower quality of service (Mohammad-Alizadeh $C$ et al., 2009, HaghparastBidgoli et al., 2010, Joolaee et al., 2006). Moreover, It has been proven that inadequate skills and knowledge of staffs are known as a utilization barrier in Iran (Haghparast-Bidgoli et al., 2010). 
Malaysia: Normally younger doctors run the public health facilities and most of the staffs are trained and older doctors run the private clinics with less trained staffs (Aljunid and Zwi, 1996). Doctors in public clinics saw more complex and chronic illnesses while in private clinics they saw more acute and minor diseases(Mimi et al., 2011).

According to Ministry of Health reports(MOH, 2013a, $\mathrm{MOH}, 2011)$ :

- Overall, there were 2.1 clinics per 10,000 populations in Malaysia. Private clinics outnumbered the public by 6.3 to 1 .

- On an average, public clinics had higher total attendances per day compared to the private.

- More than $90 \%$ of public clinics provided preventive and health promotion services.

- The median number of doctors per public clinic was 4.5 doctors.

- The majority of doctors (61.1\%) practicing in the public clinics were between the age of 25-34 years old while $75 \%$ of the doctors in the private sector had more than 10 years of experience in primary care.

- Overall $2.4 \%$ of the doctors providing primary care services in Malaysia are specialists in this field and the majority of them were in the public sector.

- Follow up was 63.3 per 100 encounters in public clinics which are more frequent compared to private (19.4 per encounters).

Iran: Mostly private sector and public sector deliver similar services to patients with different quality which is divided into two category; outcome quality and process quality (Zarei et al., 2012).

According to Statistical Center of Iran report and Ministry of Health and Medical Education (Hooi and Hooi, 2003, Statistical Center of Iran, 2013):

- Urban population in Iran has $100 \%$ primary care coverage by both public and private sectors.
- Urban family physician plan provided by government is covering more than 30 million of Iranian with at least 6900 physicians.

- 37490 doctors and 130,574 staffs are working in public sectors under the ministry of health and medical education.

- 543 public institutes, 8515 public health centers, 748 public radiology centers and 2159 public laboratories are providing health services in urban areas.

India: government facilities are less expensive and are staffed by qualified and expert personnel, most households tend to use private providers, who are not only unregulated but also often unqualified (Banerjee et al., 2008). According to Central Bureau of Health Intelligence report and Murray's study (MOHFW, 2013, Aitken, Chang \& Udeshi, 2013):

- Out of 918,303 doctors in India, only 106,813 doctors are working in public sector.

- 24,448 primary health centers, 151,684 sub centers, 5,187 community health centers in rural areas, 350 CGHS dispensaries, 1063 urban family welfare, 871 health posts and 4419 hospitals in urban areas, are providing primary health care services.

- Urban health posts cover 54,527,213 and urban family welfares cover 52,587,231 individuals.

- Per 1000 number of ailments treated, 192 individuals referred to government sector and 808 individuals referred to private sectors.

- Average medical expenditure for non-hospitalized cases in a government sector is Rs.7 and in a private sector is Rs. 299.

- The reason for selecting private health care facilities in urban area are; $62 \%$ doctor availability in private sector, $56 \%$ to get quick access, $54 \%$ less waiting time, $26 \%$ not free medicines in governmental sector, $16 \%$ can afford, and $13 \%$ lack of specialist in public sector.

Table 1 shows the total number of doctors, ratio of physicians and populations, number of physicians in public sector, number of nurses and pharmacists in Malaysia, Iran and India.

\begin{tabular}{|l|l|l|c|}
\hline & Malaysia & Iran & India \\
\hline Total number of doctors & $46,916(2012)$ & $110,000(2013)$ & $918,303(2013)$ \\
\hline Physicians/1000 Population (2012) & 0.94 & 0.89 & 0.62 \\
\hline Number of physicians in public sector & 25,845 & 37,490 & 106,813 \\
\hline Total Number of Nurses & 74,788 & 170,000 & $1,562,186$ \\
\hline Total number of public clinics in urban areas & 1039 & 8515 & NA \\
\hline
\end{tabular}

Source: (Hooi and Hooi, 2003, Iran, 2013, MOH, 2013a, National Health Profile of India, 2013) 
Financial barriers: include insurance coverage and costs of services which is directly related to the user's ability and willingness to pay for those services (Peters et al., 2008). The key factors of equity in financial risk protection and health financing are; High level of out-ofpocket expenditure, lack of comprehensive risk pooling mechanism, low level of public financing in the perspective of increasing health expenditure are key factors effecting equity in financial risk protection and health financing (Balarajan et al., 2011).

Completing the treatment has too much cost due to low insurance penetration and current insurance plans not covering medications expenses in India (Aitken, 2013). Only around $24 \%$ of Indian people are covered by any type of voluntary or social health insurance, which is generally offered through government arrangements for selected employment groups in the organized sector. Unskilled employers, agricultural labors, and lowincome farmers in the informal sector and entrepreneurs are less likely to be covered (Balarajan et al., 2011, Yip and Mahal, 2008). Studies in Iran also shows that around $10 \%$ of Iranians are not covered by any insurance so they have to spent higher proportions of their capacity to pay for health care services (Kavosi et al., 2012, Alavian, Tabatabaie et al., 2012). This issue is similar to other parts of the world's demonstrations(Xu et al., 2009).

Medication expenditure is the most important elements of out-of-pocket expenditure in India which has increased by a $2-3 \%$ compound annual growth rate over the last decade (Aitken, Chang \& Udeshi, 2013). Poverty makes people more sensitive to health care, since they seek care less than rich when they are ill, therefore, financial cost is the most important reason for them to avoid seeking care (Balarajan et al., 2011) especially for women, older people, disabled and destitute (Kapur Mehta \& Shah, 2003). In India out of pocket expenditure increased the poverty rate from $31.1 \%$ to $34.8 \%$ (Yip and Mahal, 2008). $82 \%$ of OOP expenditure spent on primary and inpatient care (Das and Hammer, 2007).On the other hand, Malaysia's stable health care system is facing challenges with raising medicines price so a large group of people are not able to pay for their medicines (Babar et al., 2007). In spite of providing totally free primary healthcare by the government of Malaysia, health care resources within the country are not optimally utilized (Noh, 2011) and a report prove that youth will refuse to use health care services due to financial constraints which is also reported for Iran (Ghafari, 2014, Tabatabaie et al., 2012).

Consultations, vaccinations and medications are provided free of charge in Malaysian public clinics. In Iran, vaccinations and some consultations (maternal and child care) are free of charge and some others are nominally priced and most of the common medications are highly subsidized by government and it is very cheap for those who are covered by insurance. In India consultations and vaccinations are provided like Iran and medications are not free.

Table 2 shows the cost of physician consultation fee, medication and vaccination fees in public clinics, health posts and health center in Malaysia, Iran and India.

Table 2: costs in public health clinics and health posts and health centers

\begin{tabular}{|l|l|c|c|}
\hline & Malaysia & Iran & India \\
\hline Consultation & Free & $\begin{array}{l}\text { Free/nominally } \\
\text { priced }\end{array}$ & $\begin{array}{c}\text { Free/nominally } \\
\text { priced }\end{array}$ \\
\hline Medication & Free & Not free & Not Free \\
\hline Vaccination & Free & Free & Free \\
\hline
\end{tabular}

Source: (Das et al., 2012, Noh, 2011, Mehrdad, 2009) 
Personal barriers: Information, education and knowledge can change the demand for health services, by influencing compliance with treatment, health seeking behavior, awareness of illness and health and health beliefs. These barriers may be further shaped by socio-cultural factors, such as cultural beliefs, religion and sex (Balarajan et al., 2011). For example, $72 \%$ of Indian women who did not give birth in a health facility reported that they did not feel that it is necessary (International Institute for Popular Sciences, 2007). Indian urban poor have limited knowledge on a proper health behavior and unaware of the services provided in health facilities and locations which leads to lower utilization and demand of health services (Agarwal et al., 2007) like programs related to maternal services(Rai \& Chauhan, 2014). On the other hand, Individuals' differences, cultural values and beliefs, poor communication and information exchange, poor coordination and cooperation and inadequate knowledge are known as barriers to access health services for Iran (Haghparast-Bidgoli et al., 2010). Some college students in Malaysia also report that work or study commitment and lack of information about services provided in public clinics lead them to not use the services(Ghafari, 2014). Women's health is an indicator of society's health which is completely ignored in many of South Asian countries like India. Gender inequality makes women more unprotected to various disease and associated mortality and morbidity. Indian women find themselves less important than men, and financially, culturally and socially dependent. In general an Indian woman is less likely to seek proper and primary care for illness, whatever the socio-economic status of the family might be (Deogaonkar, 2004). In Iran there is no association between utilization for health care services and individual characteristics such as age, gender, and marital status, but there is a higher level of utilization among women compared to men(Alavian, 2007).

The use of a service can suffer both indirect costs like loss of daily income or household duty, and direct costs which is the service or transportation expenditure. This issue exists in Iran and India (Griffiths \& Stephenson,
2001; Alavian, 2007). Another study in India shows that difficulty of access to health centers is more noticeable for mothers with lower level of education (Deogaonkar, 2004). In general, poverty is frequently associated with poor education status so there is a positive relation between earnings and higher education. An important determinant of health is education. For example, probability of a good health status increases by $5 \%$ through one additional school year. Education status not only has effect on the person's health status, but also influences the health status of the family members (Butsch et al., 2012). Similarly in Malaysia too it is proved that larger Malaysian families are more prone to poverty (Mok et al., 2007). Since measurement of socioeconomic status is poverty, which is noted determinant of health related outcomes (Newacheck et al., 1996; Brooks-Gunn \& Duncan, 1997), but, socioeconomic factors don't influence Indian's women's decisions to use maternal healthcare and places used for delivery if individuals find that they really need the services and also they do not have distance problem but the cost has significant effect on their access 'Griffiths \& Stephenson, 2001).

Healthcare Indicators: Chronic diseases are the major causes of death and disability in many countries which can be managed by primary care setting to reduce the morbidity and mortality. Primary care is the cornerstone to provide high quality and cost effective chronic diseases care especially for Malaysia since chronic diseases in Malaysia are the major cause of disability and death (around 74\%) -(Ramli \& Taher, 2008). 29.9\% of Malaysian population was above 30 years suffering from hypertension and $8.3 \%$ from diabetes in $2011(\mathrm{MOH}$, 2013b). Iran is experiencing a rapid epidemiological transition with an increase in the burden of noncommunicable diseases. Simultaneously, the country is going through demographic transition with declining vaccine preventable communicable diseases, maternal mortality, infant mortality, and birth rate. Needs will change over time as a result of increasing chronic diseases, pollution, congestion, and urbanization (Moghadam et al., 2012). 
Figure 1 shows the percentage of burden due to chronic disease in these three countries. According to World data,Malaysia and Iran have good immunization coverage. India has very high maternal mortality ratio and infant mortality.

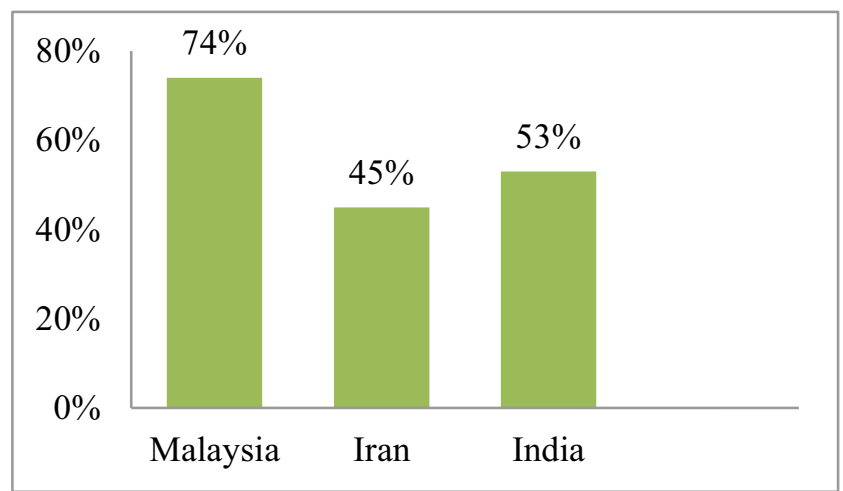

Figure 1: Burden of chronic disease

Source: (Mehrdad, 2009, Ramli and Taher, 2008, Balarajan et al., 2011)

According to World Bank data, Malaysia and Iran have good immunization coverage. India has very high maternal mortality ratio and infant mortality.

Table 3 shows some of the heath indicators in Malaysia, Iran and India.

Table 3: Health Indicators of Malaysia, India and Iran

\begin{tabular}{|l|c|l|l|}
\hline & Malaysia & Iran & India \\
\hline Death Rate (per 1000 people) & 5 & 5 & 8 \\
\hline Life Expectancy at Birth & 75 & 74 & 66 \\
\hline Infant Mortality (per 1000 live birth) & 6 & 21 & 42 \\
\hline Maternal Mortality Ratio & 29 & 21 & 200 \\
\hline $\begin{array}{l}\text { Birth attended by Skilled Health } \\
\text { Personnel (\%) }\end{array}$ & 99 & 97 & 58 \\
\hline Immunization Coverage & 97 & 98 & 72 \\
\hline
\end{tabular}

Source: (WorldBank, 2013)

\section{DISCUSSION}

Malaysia has huge gains in health and in the improvement of health system during the past five decades since Independent and trying to improve the national health, and to decrease inequalities in access and use of health care services. In the past decade, the public sector has expanded faster and overall levels of use and utilization has increased significantly $(\mathrm{MOH}$, 2013b). Challenges faced by the current primary care system in Malaysia include;

- Doctors with lower experience in public clinics compare to private

- Lack of information about services provided by public clinics

- Changes of health needs health challenges

- Transportation and distance
- Available medication and medication cost

- Waiting time

Iran has well-structured health system. A primary health center network has been established through the country since the revolution. Urban health posts and health centers in urban areas have been established, managed and administered through district health centers by MOHME supervision. Primary health care services are provided by the public sector across the country (Moghadam et al., 2012) in urban area through health posts which covers more than $34,500,000$ individuals and family physician program which covers more than 30 million of urban population. Challenges faced by the current primary care system in Iran;

-Health transition and changing demand pattern and new needs in health

-Transportation

-Number of physicians and nurses and waiting time

India government have concentrated on investments in structure and medical equipment, combined with expansions in the public delivery of primary care services and the number of skilled health personnel to increase the quality of health care. In many urban areas, primary health care facilities are not available (MOHFW, 2003).

Challenges faced by the current primary care system in India:

-Behavioral factors, cultural believes, gender inequality and education

-High out of pocket expenditures and Lack of Insurance coverage and inflation in health spending such as medication cost

-Inadequate human resources and physical infrastructure and waiting time

-An imbalance in resource allocations

All these issues affect the demand for appropriate health care(Balarajan et al., 2011).

Access concern exists in all these three countries, types and sources of the barriers are varying. Differences influence public expectations and opinion of policy leaders. In general, Malaysia has a good coverage of public health care services through public clinics and the services are accessible for the most of the population free of charge. However, there are some Structural and personal barriers in Malaysia. In the recent years, Iran has enjoyed improvement population health indicators 
such as life expectancy, under 5 mortality rate, infant mortality, and maternal mortality by providing more primary health care services though public sector and provides some services for free such as vaccinations and prenatal care. However, there are number of barriers for Iranian to not fully utilize public services. In India, all Structural, financial and personal barriers force poor people to utilize private clinics and hospitals while public health posts and hospitals provide the same services either free or nominally priced.

\section{RECOMMENDATION}

Generally, most of the previous works are based on private and public sectors and/or hospitals. Among the available studies conducted on health care access, only a limited number of them paid close attention to public clinics, even though the former care section is playing an important role in the urban poor health care. Moreover, in terms of information availability, the accurate and precise data are not reported by the MOHME and Statistical Center of Iran. There is a need to conduct a cross cultural survey and organized scrutiny to identify the barriers to public clinics' access.

\section{ACKNOWLEDGEMENT}

The researchers would like to render their heartily gratitude to the University of Malaya research grant for offering the financial support for the study under the Equitable Society Research Cluster (Grant Number: RP018D-14SBS), Postgraduate Research Grant (PPP) Research (Grant Number: PG141-2015A) and Centre for Poverty and Development Studies (Grant Number: PD006-2017).

\section{REFERENCES}

Agarwal, S., Satyavada, A., Kaushik, S. \& Kumar, R. (2007). Urbanization, urban poverty and health of the urban poor: status, challenges and the way forward. Demography India, 36 (1), pp 121-134.

Aitken,M. A. B. M., Chang, M. \& Udeshi, A. (2013). Understanding Healthcare Access in India What is the current state? : IMS Institute for Healthcare Informatics. Retrieved From: https://www.slideshare.net/IMSHealth_APAC/ims-executive-summaryindiaeversionfinal 2

Alavian, S. M. 2007. Determinants of seeking needed outpatient care in Iran: results from a national health services utilization survey. Archives of Iranian medicine, 10, pp 439-445.

Aljunid, S. M. \& Zwi, A. B. (1996). Differences in public and private health services in a rural district of Malaysia. The Medical journal of Malaysia, 51 (4), pp 426-436.

Arcury, T. A., Preisser, J. S., Gesler, W. M. \& Powers, J. M. (2005). Access to transportation and health care utilization in a rural region. The Journal of Rural Health, 21 (1), pp 31-38.

Asadi-Lari, M., Sayyari, A. A., Akbari, M. E. \& Gray, D. (2004). Public health improvement in Iran-lessons from the last 20 years. Public Health, 118 (6), pp 395-402.

Asian Development Bank (2014). Health Issues in Asia and the Pacific. Retrieved From: https://www.adb.org /sectors/health/issues.

Babar, Z. U. D., Ibrahim, M. I. M., Singh, H., Bukahri, N. I.\& Creese, A. (2007). Evaluating drug prices, availability, affordability, and price components: implications for access to drugs in Malaysia. PLoS Medicine, 4 (3), pp 466-475.

Balarajan, Y., Selvaraj, S. \& Subramanian, S. (2011). Health care and equity in India. The Lancet, 377 (9764), pp 505-515.

Banerjee, A. V., Glennerster, R. \& Duflo, E. (2008). Putting a Band-Aid on a corpse: Incentives for nurses in the Indian public health care system. Journal of the European Economic Association, 6 (2-3), pp 487-500.

Basu, S., Andrews, J., Kishore, S., Panjabi, R. \& Stuckler, D. (2012). Comparative performance of private and public healthcare systems in low-and middle-income countries: a systematic review. PLoS medicine, 9 (6).

Berendes, S., Heywood, P., Oliver, S. \& Garner, P. (2011). Quality of private and public ambulatory health care in low and middle income countries: systematic review of comparative studies. PLoS medicine, 8 (4), pp 1-10.

Brooks-Gunn, J. \& Duncan, G. J. (1997). The effects of poverty on children. The future of children, 7 (2), pp $55-71$.

Butsch, C., Sakdapolak, P. \& Saravanan, V. (2012). Urban health in India. Internationales Asienforum, 43 (1-2), pp 13-32.

Chander Shekhar, F. R. (2005). National Report on Evaluation of Functioning of Urban Health Posts/ Urban Family Centers in India. International 
Institute for Population Sciences. Retrieved From: http://iipsindia.org/publications05_b_13c.htm.

Das, J. \& Hammer, J. (2007). Location, location, location: residence, wealth, and the quality of medical care in Delhi, India. Health Affairs, 26 (3), pp w338w351.

Das, J., Holla, A., Das, V., Mohanan, M., Tabak, D. \& Chan, B. (2012). In urban and rural India, a standardized patient study showed low levels of provider training and huge quality gaps. Health Affairs, 31 (12), pp 2774-2784.

Deogaonkar, M. (2004). Socio-economic inequality and its effect on healthcare delivery in India: inequality and healthcare. Electronic Journal of Sociology.Retrieved From: https://www.sociology org/ejs-archives/vol8.1/deogaonkar.html

Griffiths, P. \& Stephenson, R. (2001). Understanding users' perspectives of barriers to maternal health care use in Maharashtra, India. Journal of biosocial science, 33 (3), pp 339-359.

Guagliardo, M. F. (2004). Spatial accessibility of primary care: concepts, methods and challenges. International journal of health geographics, 3 .

Haghparast-Bidgoli, H., Hasselberg, M., Khankeh, H., Khorasani-Zavareh, D. \& Johansson, E. (2010). Barriers and facilitators to provide effective prehospital trauma care for road traffic injury victims in Iran: a grounded theory approach. BMC emergency medicine, 10.

Heller, P. S. (1982). A model of the demand for medical and health services in Peninsular Malaysia. Social Science \& Medicine, 16(3), pp 267-284.

Hooi, S. \& Hooi, S. (2003). Utilization of ophthalmic services by foreign nationals in Johor: a review of 452 patients. Medical Journal of Malaysia, 58 (4), pp 579-586.

Joolaee, S., Nikbakht-Nasrabadi, A., Parsa-Yekta, Z., Tschudin, V. \& Mansouri, I. (2006). An Iranian perspective on patients' rights. Nursing Ethics, 13 (5), pp 488-502.

Kapur Mehta, A. \& Shah, A. (2003). Chronic poverty in
India: Incidence, causes and policies. World Development, 31 (3), pp 491-511.

Kavosi, Z., Rashidian, A., Pourreza, A., Majdzadeh, R., Pourmalek, F., Hosseinpour, A. R., Mohammad, K. \& Arab, M. (2012). Inequality in household catastrophic health care expenditure in a lowincome society of Iran. Health policy and planning, 27 (7), pp 613-623.

Laquian, A. A. (2004). Who are the poor and how are they being served in Asian cities? Paper presented at the "Forum on Urban Infrastructure and Public Service Delivery for the Urban Poor, Regional Focus: Asia," sponsored by the Woodrow Wilson International Center for Scholars and the National Institute of Urban Affairs, India Habitat Centre, New Delhi.

Mahin Ghafari, K. S., Masoud Amiri. (2014). Barriers to Utilization of Health Services: Perception of Post secondary School Malaysian Urban Youth.

Mehrdad, R. (2009). Health system in Iran. Japan Medical Association Journal, 52 (1), pp 69-73.

Mimi, O., Tong, S., Nordin, S., Teng, C., Khoo, E., Abdul-Rahman, A., Zailinati, A., Lee, V., Chen, W., Shihabudin, W., Norida, M. \& Fauziah, Z. (2011). A comparison of morbidity patterns in public and private primary care clinics in Malaysia. Malaysian Family Physician, 6(1), pp 19-25.

Moghadam, M. N., Sadeghi, V. \& Parva, S. (2012). Weaknesses and challenges of primary healthcare system in Iran: a review. The International journal of health planning and management, 27 (2), pp e121-e131.

MOH (2011). National Healthcare Establishments \& Workforce Statistics (Primary Care) 2008-2009.

MOH (2013) a. Health Fact 2013.

MOH (2013) b. Malaysia Health Care Demand Analysis.

Mohammad-Alizadeh C, S., Wahlström, R., Vahidi, R., Nikniaz, A., Marions, L. \& Johansson, A. (2009). Barriers to high-quality primary reproductive health services in an urban area of Iran: views of public health providers. Midwifery, 25 (6), pp 721-730.

MOHFW (2003). Public Health Care System. Planing 
Commision Government of India.

MOHFW (2013). National Health Profile 2013.

Mok, T. Y., Gan, C. \& Sanyal, A. (2007). The determinants of urban household poverty in Malaysia. Journal of Social Sciences, 3 (4), pp 190196.

Newacheck, P. W., Hughes, D. C. \& Stoddard, J. J. (1996). Children's access to primary care: differences by race, income, and insurance status. Pediatrics, 97 (1), pp 26-32.

Noh, K. M. (2011). Primary Health Care Reform in 1CARE for 1 Malaysia. International Journal of Public Health Research (Special Issue), pp 50-56.

World Health Organization/WHO (2012). Malaysia health system review. Retrieved From: http://apps. who.int/iris/handle/10665/206911.

Peter Wennerholm, A. M. S. (2013). India's Health system.

Peters, D. H., Garg, A., Bloom, G., Walker, D. G., Brieger, W. R. \& Rahman, M. H. (2008). Poverty and access to health care in developing countries. Annals of the New York Academy of Sciences, 1136, pp 161-171.

National Health Profile of India (2013). Human Resource in Health Sector. Retrieved From: http://cbhidghs.nic.in/WriteReadData/1892s/Human\%2 0Resources\%20in\%20Health\%20Sector-2013.pdf

Rai, A. K. \& Chauhan, B. G. (2014). Inequality in utilization of maternal health care services among teenage married women in uttar pradesh: evidences form nfhs-3. Global Journal of Multidisciplinary Studies, 3 (10), pp 70-89.

Ramli, A. \& Taher, S. (2008). Managing chronic diseases in the Malaysian primary health care-a need for change. Malaysian Family Physician, 3 (1), pp 7-13.

Rashidian, A. (2014). Establishing urban primary health care: experience from Iran Tehran University of Medical Sciences.
Sciences, I. I. F. P. (2007). India National Family Health Survey (NFHS-3), 2005-06, International Institute for Population Sciences.

Sclar, E. D., Garau, P. \& Carolini, G. (2005). The 21st century health challenge of slums and cities. The Lancet, 365 (9462), pp 901-903.

Shah, A. (2014). Health Issues. Retrieved From: http://www.globalissues.org/issue/587/health-issues.

Shepard, D. S., Savedoff, W. \& Hong, P. K. (2002). Health care reform initiatives in Malaysia. Retrieved From: http://www.who.int/health _financing/documents/malaysia-reform-initiatives.pdf.

Shook, M.(2005).Transportation barriers and health access for patient attending a community health center. Retrieved From: http://web.pdx. edu/ jdill/ Files/Shook_access_transportation_chc.pdf.

TABATABAIE, M. G., ZAHRA, M. \& ABOUALI, V. 2012. Home birth and barriers to referring women with obstetric complications to hospitals: a mixedmethods study in Zahedan, southeastern Iran. Reproductive health, 9.

WHO (2008). The World Health Report 2008. Retrieved From: http://www.who.int/whr/2008/en/

WORLDBANK 2013. World Bank Website: World Bank Group.

Xu, K., Saksena, P., Carrin, G., Jowett, M., Kutzin, J. \& Rurane, A. (2009). Access to health care and the financial burden of out-of-pocket health payments in Latvia. World Health Organization, Geneva. Retrieved From:http://www.who.int/health_financing/documents/pb_e_09_1-oopslat.pdf

Yip, W. \& Mahal, A. (2008). The health care systems of China and India: performance and future challenges. Health Affairs, 27 (4), pp 921-932.

Zarei, A., Arab, M., Froushani, A. R., Rashidian, A. \& Tabatabaei, S. M. G. (2012). Service quality of private hospitals: The Iranian Patients' perspective. $B M C$ health services research, 12,31 . 